\title{
OS “OBJETOS DE ESTUDO” DA PESQUISA EM ENSINO DE FÍSICA SEGUNDO PESQUISADORES BRASILEIROS
}

\author{
Olga L. Castiblanco Abril* \\ Roberto Nardi**
}

RESUMO: Nesta pesquisa, optamos por investigar junto a pesquisadores em ensino de física brasileiros sobre os "objetos de estudo" deste campo, numa tentativa de identificar algumas características que permitam organizar núcleos de conteúdos a serem ensinados numa disciplina de Didática da Física. Também perguntamos sobre os métodos de pesquisa e os principais referenciais teóricos, além de realizar uma sucinta caracterização dos perfis profissionais desses pesquisadores, a fim de ampliar opções de compreensão das respostas à questão. Para tanto, aplicamos um questionário elaborado e validado, especificamente para cada pesquisador. Através da análise dos dados obtidos pudemos concluir que os "objetos de estudo" da pesquisa em ensino de física no Brasil são diversos, mas possíveis de ser entendidos em campos temáticos inter-relacionados. Além disso, constatamos o caráter multidisciplinar da pesquisa na área, o que nos permite deduzir que o ensino da Didática da Física deve ter esse mesmo caráter.

Palavras-chave: Ensino de física. Pesquisa em ensino de física. Didática da Física.

THE “OBJECTS OF STUDY” FROM RESEARCH IN PHYSICS TEACHING ACCORDING TO BRAZILIAN RESEARCHERS

ABSTRACT: In this study, we investigate "objects of study" among Brazilian researchers in Physics Teaching, in an attempt to identify characteristics that allow the organization of themes or contents to be taught in a course called Didactics of Physics. Moreover, we decided to ask about the research methods and the main theoretical frameworks, as well as a succinct characterization of these researchers' professional profiles, in order to broaden the answers' understanding of the question. Such questions were asked through a validated questionnaire designed specifically for each researcher. Data collected allowed us to conclude that the "objects of study" in physics teaching's research in Brazil are diverse, but possible to be understood in interrelated thematic fields. We also found the research's multidisciplinary nature in the area, which allows us to deduce that teaching of Didactics of Physics must have the same character.

Keywords: Physics Teaching. Research in Physics Teaching. Didactics of Physics.

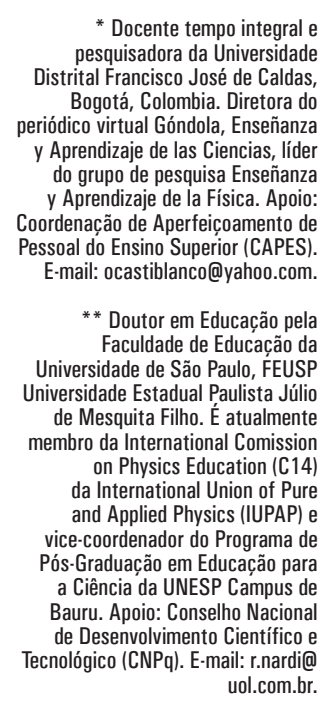
uol.com.br. 
LOS “OBJETOS DE ESTUDIO” DE LA INVESTIGACIÓN EN ENSEÑANZA DE LA FÍSICA DE ACUERDO CON INVESTIGADORES BRASILEROS

RESUMEN: En esta investigación, optamos por explorar junto a investigadores brasileros en enseñanza de la física, acerca de los "objetos de estudio" de este campo, con el fin de identificar algunas características que permitan organizar núcleos de contenidos a ser enseñados en una asignatura de Didáctica de la Física. También preguntamos acerca de los métodos de investigación y los principales referenciales teóricos, además de realizar una breve caracterización de los perfiles profesionales de estos investigadores, buscando ampliar opciones de comprensión de las respuestas a la pregunta de investigación. Para esto, aplicamos un cuestionario elaborado y validado específicamente para cada investigador. A partir del análisis de datos obtenido, pudimos concluir que los "objetos de estudio" de la investigación en enseñanza de la física en Brasil son diversos, pero posibles de ser comprendidos en campos temáticos interrelacionados. Además, constatamos el carácter multidisciplinar de la investigación en el área, que nos permite deducir que la enseñanza de la Didáctica de la Física debe tener el mismo carácter.

Palabras clave: Enseñanza de la Física. Investigación en Enseñanza de la Física. Didáctica de la Física. 


\section{INTRODUCุÃO}

No Brasil, segundo os trabalhos de Nardi (2005) e Nardi e Almeida (2007), a área de ensino de ciências é um campo de conhecimento que se consolidou como resultado do compartilhamento de uma série de preocupações comuns, e não da sua organização em torno de um paradigma hegemônico. Quer dizer, não há unanimidade nos critérios que orientam a pesquisa no ensino de ciências, nem as transformações na formação de professores de ciências. Mesmo assim, em Nardi (2005), o autor caracterizou a área por meio de sete itens que unem os pesquisadores: 1) o caráter inter- ou multidisciplinar da área; 2) o reconhecimento de saberes específicos para a prática e a pesquisa no ensino de ciências; 3) a utilização de diversas disciplinas na pesquisa, diferenciando-se de processos de pesquisa direcionados pela física; 4) as formas de avaliar os resultados de pesquisa com uma perspectiva stricto sensu; 5) a presença da história e da filosofia das ciências na pesquisa da área; 6) a diversidade de objetos de pesquisa, referenciais teóricos e metodológicos em função das diferentes perspectivas e contextos; e 7) o lócus dos pesquisadores, mais próximo da área de "conteúdos" e de seus referenciais epistemológicos ou históricos e filosóficos, ou, mais próximo dos aportes que marcam a área da "educação" (psicologia, sociologia, etc.).

Outro fator colocado pelo autor é o consenso sobre a inscrição da área nas ciências humanas, a qual mantém uma tensão a respeito da diferença entre formar pesquisadores em educação e formar pesquisadores no ensino, e ainda sobre a identificação das pesquisas realizadas no campo com as ciências humanas aplicadas ou com ciências sociais aplicadas. Nesse sentido, encontram-se também estudos como o de Megid (2007), que, ao fazer uma descrição da pesquisa realizada entre as décadas de 70 e 90, refere-se a ela como uma "área de ensino e pesquisa que abrange estudos e ações educacionais no campo das denominadas ciências da natureza (biologia, física, química e geociências)" (MEGID, 2007, p. 341), sendo os resultados de pesquisa direcionados para os níveis de educação básica e superior. $\mathrm{O}$ autor mostra como os conteúdos dessas pesquisas dão grande ênfase aos aspectos metodológicos do ensino, mais do que aos conhecimentos científicos veiculados na escola.

Por sua vez, Delizoicov (2007) fez uma análise epistemológica da produção da pesquisa em ensino de ciências, a partir da perspectiva de Fleck. Ele concluiu que a área constitui-se em "um campo social de produção de conhecimento, caracterizando-se como autônoma em relação a outros campos do saber, mas mantendo inter-relações, em distintos níveis de aproximação, com essas áreas". (DELIZOICOV, 2007, p. 440).

Diante dessas considerações, colocamo-nos a questão de como encontrar parâmetros que orientem a atividade do professor formador de professores e pesquisadores em ciências. Ressaltamos a necessidade de se trabalhar por definições cada vez mais claras e por consenso sobre alguns aspectos básicos, por exemplo, o que e como ensinar para a formação em ensino e para a pesquisa em ensino. 
Nesse sentido, apresentamos a seguir os resultados de uma pesquisa que aponta o que pesquisadores em ensino de física consideram como seus objetos de pesquisa, o que nos permite construir reflexões que procurem dar resposta a essa questão, ao oferecer um panorama de aspectos comuns ou tendências nas maneiras de entender a pesquisa nessa área que, portanto, poderiam ser subsídios a serem considerados na formação de professores de ciências.

\section{Relação entre a pesquisa em ensino de física e a didática da física como disciplina}

Partimos do pressuposto de que ensinar Didática da Física implica o ensino de conhecimentos para que o professor compreenda o que é que vai ensinar, como, por que e para quem. Assim, esse tipo de conhecimento vai além dos conteúdos das ciências exatas, uma vez que são necessários conhecimentos das ciências humanas e das ciências sociais relacionados à questão do ensino da física. Por isso consideramos que os resultados de pesquisa no campo de ensino de física podem auxiliar na consolidação dos conteúdos e das metodologias a serem trabalhados em um curso de Didática da Física. Consideramos, entretanto, que a literatura nesse campo oferece-nos hoje um panorama diverso de formas de entender a Didática da Física, o qual nos gera questionamentos quando pensamos nos critérios para organizar conteúdos a serem trabalhados no ensino da Didática da Física. Todos esses questionamentos motivaram esta pesquisa e nos levaram a pensar na relação que existe entre a pesquisa em ensino de física e o que se propõe na formação de professores, a fim de educá-los para o ensino dessa disciplina: de que maneira podemos aproveitar os conhecimentos de diversas disciplinas para ensinar aos licenciandos a ensinar física? Que tipos de atividades seriam as mais apropriadas para propiciar a aprendizagem de conhecimentos de diversas disciplinas a fim de ensinar a resolver um problema de ensino de física? Como ir do simples ao complexo, ou de níveis básicos para níveis superiores no ensino da Didática da Física? Como decidir qual a sequência de conteúdos seria a mais apropriada?

Atualmente esse propósito torna-se mais viável, ao considerarmos a existência das diversas linhas de pesquisa da área, que estudam, cada vez com maior profundidade, a integração de conhecimentos vindos de disciplinas como Filosofia, História, Epistemologia, Linguagem, etc., para enriquecimento de novas perspectivas para o ensino na formação de professores.

Para o caso da formação de professores de física, é preciso, então, considerar resultados de pesquisa que permitam orientar o licenciando, tanto para a maior compreensão do conhecimento científico que vai ensinar (a física), quanto para o conhecimento que lhe permita entender o contexto no qual vai ensinar, os objetivos de ensinar, e as estratégias de ensino, a fim de atingir os objetivos educacionais propostos.

Mas como o professor universitário, formador de professores, pode orientar o licenciando a inter-relacionar diversos conhecimentos visando formá-lo para que organize suas próprias estratégias de ensino?

Neste ponto consideramos vital estabelecer uma relação entre as propos- 
tas dos pesquisadores da área e a prática profissional do ensino dessa área. Por exemplo, no Brasil existe uma área de pesquisa em ensino de ciências e, dentro dessa área, existe uma ampla diversidade de linhas de pesquisa que consideram contribuições de diversos campos do conhecimento para elaborar propostas de ensino, tanto na formação inicial como continuada de professores, conhecimentos que podem ser aproveitados para repensar as práticas de ensino.

\section{A procura pelo grupo de pesquisadores em ensino de física e a consulta realizada}

Nossa busca começou na Plataforma Lattes ${ }^{1}$ do Conselho Nacional de Desenvolvimento Científico e Tecnológico (CNPq) com base nos filtros: 1. Doutores; 2. Bolsistas de Produtividade do CNPq; 3. Grande Área de Ciências Humanas; 4. Área de Educação.

A utilização desses filtros teve como propósito encontrar pesquisadores cujas trajetória e produção fossem reconhecidas e visíveis. Como resultado, encontramos 741 pesquisadores na área de ciências humanas/educação, o que nos levou a revisar cada um dos currículos, procurando aqueles que tivessem formação em física, ensino de física e/ou áreas afins, o que nos ofereceu um grupo de 36 pesquisadores.

Tendo consciência de que alguns pesquisadores reconhecidos da área, provavelmente, não estivessem inscritos nessa plataforma no momento da busca, mas têm produzido importantes contribuições na área, buscamos também esses pesquisadores entre os conferencistas convidados para expor sobre temáticas relacionadas ao ensino e a aprendizagem da física nos seguintes eventos acadêmicos: Simpósio Nacional de Ensino de Física (SNEF, 2009, 2011), Encontro de Pesquisa em Ensino de Física (EPEF, 2006, 2008) e Encontro Nacional de Pesquisa em Ensino de Ciências (ENPEC, 2009, 2011). Encontramos 11 pesquisadores a mais, formando uma amostra de 47 pesquisadores.

Procuramos então analisar os 47 currículos dos pesquisadores da amostra a partir da produção específica sobre resultados de pesquisa em ensino e aprendizagem da física. Percebemos que a maioria declara linhas de pesquisa na área de ensino de ciências; entretanto, apenas 24 deles têm produção específica no ensino da física, sendo estes últimos, os pesquisadores escolhidos como a amostra final, para os quais elaboramos os respectivos questionários.

A escolha do questionário como técnica de coleta de informação se deu devido às vantagens que esse recurso oferece ao permitir contatar os pesquisadores pelo correio, estando eles localizados em diversos pontos do país e também ao permitir sua resposta em diferentes tempos, dependendo da disponibilidade do consultado.

Partimos do pressuposto de que o objetivo deste estudo era encontrar informações que contribuíssem para responder à questão de pesquisa, sobre possíveis conteúdos a serem ensinados na formação de professores de física. Assim, elaboramos um questionário com seis perguntas, das quais duas eram fechadas, três foram dependentes e uma foi aberta. 
No Quadro 1 apresentamos o conteúdo, o objetivo, a forma e a tipologia das questões, embasando-nos na proposta teórica sobre elaboração de questionários apresentada por Gil (2008, p. 121), que reconhece a construção de questionários como um procedimento técnico que precisa de cuidados, como "constatação de sua eficácia para verificação dos objetivos; determinação da forma e do conteúdo das questões; quantidade e ordenação das questões; construção das alternativas; apresentação do questionário e pré-teste do questionário."

Quadro 1- Descrição do tipo de questões do questionário

\begin{tabular}{|c|c|c|c|}
\hline 1 & $\begin{array}{l}\text { Identificação da atividade } \\
\text { profissional, por meio de dados } \\
\text { como: e-mail, vínculo empregatício, } \\
\text { formação acadêmica, área, grupo de } \\
\text { pesquisa em que atua, função dentro } \\
\text { do grupo e linhas de pesquisa. }\end{array}$ & $\begin{array}{l}\text { Caracterizar a atividade } \\
\text { profissional e mapear } \\
\text { as possíveis linhas de } \\
\text { pesquisa na área. }\end{array}$ & $\begin{array}{l}\text { Fechada/ Questão } \\
\text { sobre fatos }\end{array}$ \\
\hline 2 & $\begin{array}{l}\text { Identificação dos instrumentos } \\
\text { e métodos de coleta e análise } \\
\text { de dados para cada um dos } \\
\text { projetos desenvolvidos por cada } \\
\text { pesquisador e registrados no } \\
\text { currículo na última década. }\end{array}$ & $\begin{array}{c}\text { Caracterizar o tipo de } \\
\text { pesquisa que desenvolve. }\end{array}$ & $\begin{array}{l}\text { Dependente/ Questão } \\
\text { sobre padrão de } \\
\text { ação. }\end{array}$ \\
\hline 3 & $\begin{array}{l}\text { Enquadramento das pesquisas } \\
\text { dentro das áreas temáticas } \\
\text { estabelecidas nos eventos } \\
\text { acadêmicos EPEF e SNEF. }\end{array}$ & $\begin{array}{l}\text { Detectar as tendências } \\
\text { de tópicos de pesquisa no } \\
\text { grupo de pesquisadores. }\end{array}$ & $\begin{array}{l}\text { Fechada/ Questão } \\
\text { sobre fatos }\end{array}$ \\
\hline 4 & $\begin{array}{l}\text { Identificação dos referenciais } \\
\text { que fundamentam os resultados } \\
\text { apresentados na produção } \\
\text { bibliográfica da última década, a } \\
\text { partir de livros citados. }\end{array}$ & $\begin{array}{l}\text { Mapear os principais } \\
\text { referenciais teóricos, nos } \\
\text { quais se fundamentam as } \\
\text { pesquisas. }\end{array}$ & $\begin{array}{l}\text { Dependente/ Questão } \\
\text { sobre conhecimentos }\end{array}$ \\
\hline 5 & $\begin{array}{c}\text { Idem ao anterior, mas relacionando } \\
\text { os artigos citados. }\end{array}$ & Idem ao anterior. & Idem ao anterior \\
\hline 6 & $\begin{array}{l}\text { Pergunta sobre o que os } \\
\text { pesquisadores consideram ser os } \\
\text { "objetos de pesquisa" da pesquisa } \\
\text { em ensino de física. }\end{array}$ & $\begin{array}{c}\text { Teorizar sobre o que os } \\
\text { pesquisadores da área } \\
\text { entendem sobre o que } \\
\text { deve ser pesquisado nesse } \\
\text { campo. }\end{array}$ & $\begin{array}{c}\text { Aberta/ Questão } \\
\text { sobre conhecimentos }\end{array}$ \\
\hline
\end{tabular}

Uma versão primeira do questionário foi aplicada a um pesquisador da área como pré-teste e, após revisão, foi aplicada a um segundo pesquisador, ambos não pertencentes à amostra. Sua versão final foi posteriormente discutida e revisada entre os participantes do grupo de pesquisa do qual os autores fazem parte. 
Esse processo permitiu refinar as questões em termos de síntese dos conteúdos e da semântica linguística, permitindo sua validação.

Visando reduzir o tempo dedicado pelos pesquisadores para responder às primeiras cinco perguntas, fizemos um levantamento de informações explícitas em seus currículos na plataforma Lattes e em cada diretório do grupo de pesquisa, preenchendo previamente as respostas de identificação profissional, de forma que, ao receber o questionário, o pesquisador apenas confirmasse ou retificasse as informações.

A ordem das cinco primeiras questões foi organizada de forma que o pesquisador pensasse previamente sobre o tema tratado na questão seis: quais são os "objetos de pesquisa" da pesquisa em ensino de física? Esta última questão é aberta e foi redigida procurando não sugerir respostas para possibilitar diversas interpretações. No final, obtivemos resposta de 15 pesquisadores, quantia que consideramos positiva, por se tratar de aproximadamente $63 \%$ das opções possíveis da amostra.

Os textos dessas respostas foram estudados com técnicas de análise de conteúdo na perspectiva de Bardin (2002). O procedimento teve as seguintes etapas: pré-análise, exploração do material e tratamento dos resultados, inferência e interpretação. Na pré-análise procuramos tendências temáticas para cada questão, identificando, por exemplo, a presença ou frequência de aparição de temas, como, por exemplo, atuação em grupos de pesquisa, linhas de pesquisa, tipos de referenciais ou fundamentação teórica utilizada. $\mathrm{Na}$ exploração do material estabelecemos unidades de registro e de contexto, por exemplo, produção acadêmica dos pesquisadores na última década e problemas tratados em suas pesquisas. Assim, para categorizar, fizemos uma classificação das tendências de pesquisa, utilizando características como perfil profissional, tipo de produção especifica para o ensino de física, principais metodologias de pesquisa utilizadas e principais referenciais teóricos utilizados para fundamentar suas pesquisas.

A apresentação dos resultados a seguir não é feita na ordem das questões, mas começando com a análise sobre as respostas da questão seis. Para a análise específica das respostas a essa questão, foram desenvolvidas quatro etapas: unitarização, categorização, captura do novo emergente e interpretação, na perspectiva de Moraes e Galiazzi (2007).

$\mathrm{Na}$ unitarização estudamos as respostas procurando as expressões que respondessem diretamente à questão. Percebemos, então, que não era possível extrair nenhuma palavra das expressões originais dos autores, pelo fato de serem expressões curtas e diretas. Assim, para encontrar as categorias, fomos buscando expressões de consenso entre os pesquisadores, ou seja, expressões comuns ou que apontassem para ideias similares, uma vez que já tínhamos percebido que isso ocorria em função do perfil profissional de cada entrevistado, por exemplo, comparando o tipo de pesquisa que desenvolvem, já que, nas respostas às primeiras cinco questões, indicaram que alguns trabalham 
especificamente estudando processos que ocorrem ao interior da sala de aula, enquanto outros aprofundam em estudos sobre políticas educacionais e outros na caracterização da pesquisa em ensino ou formação de professores de ciências.

As categorias encontradas nos permitiram propor núcleos temáticos que obviamente estão inter-relacionados, uma vez que, embora os pesquisadores tenham algumas preferências, discutem problemáticas gerais do campo de ensino de ciências. A partir daí organizamos a apresentação dos resultados a seguir.

\section{Maneiras de entender os "objetos de pesquisa" na pesquisa em ensino de física}

Dentre os fatores que incidem nas condições de produção das respostas ao questionário, vale ressaltar:

- o fato de todos os questionados serem detentores de um saber científico, como pesquisadores, o que permite caracterizar o conjunto de respostas como um discurso científico;

- $\quad$ o fato de termos colocado a questão aberta depois de cinco questões fechadas, que focam nas ideias sobre o campo da pesquisa em ensino de física;

- o fato de ser uma resposta escrita e não oral, o que limita a linguagem e obriga, de certo modo, a elaborar respostas curtas que certamente representam suas ideologias, mas que não podem ser tomadas como completas, uma vez que os pesquisadores possivelmente teriam muito mais a falar, se fossem pedidas explicações ou ampliações, e;

- o fato de a questão conter aspas na expressão "objetos de pesquisa" que, de um lado, coloca a ênfase neste aspecto e, de outro, indica que o significado desta expressão deve ser decifrado pelo pesquisador ou, pelo menos, pode ser interpretado de diversas formas, a fim de não orientar uma determinada resposta.

Para analisar as respostas, organizamos o texto a partir de quatorze de um total de quinze questões, (já que um dos pesquisadores não respondeu à questão seis) e fomos à procura das pressuposições e das polêmicas, entendendo as pressuposições como aquelas ideias que não se assumem explicitamente, mas que estão representadas no enunciado da resposta; e as polêmicas, como presentes nas negações ou reflexões colocadas.

Constatamos que praticamente todas as respostas podem ser interpretadas de diferentes formas, ou seja, entendemos que, nessa amostra de pesquisadores, não há um consenso sobre o que seriam os objetos de pesquisa da área, fato que é natural se entendemos que atuam em universidades e grupos diferenciados. Isso pode se constituir em um obstáculo para detectar critérios orientadores que permitam formular estratégias para a educação de novos pesquisadores na área, por exemplo, na formação inicial de professores. 
Numa tentativa de encontrar pontos de encontro ou desencontro, procuramos observar as principais características de seus depoimentos. A primeira grande diferença detectada foi entre os pesquisadores que acreditam que podem se referir a alguns "objetos de pesquisa" e aqueles que consideram que não é possível falar em "objetos de estudo" da área. Posteriormente, analisamos os termos com que se expressaram os pesquisadores que consideram possível falar em "objetos de pesquisa”. Percebemos que alguns elaboraram uma lista de objetos definidos, enquanto outros consideram que existem objetos gerais que estudam grandes campos, dentro dos quais há objetos específicos. Outros pesquisadores consideram que não há objetos gerais, mas categorias abrangentes, dentro das quais se encontram objetos específicos.

Assim, classificamos as respostas em quatro tipos de sentidos:

- No primeiro, consideram-se objetos de pesquisa gerais, que se desdobram em objetos específicos;

- No segundo, existem múltiplos objetos que se agrupam em diversas categorias. Essas categorias são os grandes campos de comunicação de resultados de pesquisa em eventos acadêmicos;

- No terceiro, os objetos podem ser listados como um conjunto definido de aspectos que se restringem a seu campo de ação;

- No quarto, a pergunta pelos "objetos de pesquisa" não é possível de ser respondida.

É importante observar que não necessariamente alguns sentidos são opostos aos outros, mas que às vezes se aproximam e às vezes se distanciam.

Para citar as respostas textuais dos pesquisadores, utilizaremos o código (P) seguido de um número que foi outorgado aleatoriamente. Por exemplo, na fala do pesquisador dois (P2) distingue-se o primeiro sentido, segundo o qual existem objetos gerais e objetos específicos. Salientamos que estamos apresentando as respostas dos pesquisadores na íntegra, tal como foram redigidas por eles.

P2: Os "objetos de pesquisa" da Pesquisa em Ensino de Física acabaram por se espalhar, de certo modo, nas áreas temáticas nas quais as pesquisas têm, historicamente, sido agrupadas. Assim, a Formação do Professor de Física, grosso modo, poderia ser considerada um "objeto de pesquisa", assim como os Currículos ou a Avaliação. Em minha opinião, tais "objetos de pesquisa" poderiam ser desdobrados, porém, em objetos de pesquisa mais específicos, tais como (num primeiro nível, para Formação de Professores, p.ex.): formação inicial, continuada, a distância, em espaços não formais etc.

Outro grande "objeto de pesquisa" da Pesquisa em Ensino de Física é o próprio processo de ensino-aprendizagem de conceitos científicos, midiatizado pelos conteúdos da Física. Também aqui existem desdobramentos (objetos de pesquisa mais específicos), como p.ex.: o papel da linguagem no processo de ensino-aprendizagem de conceitos científicos; o papel da experimentação no processo de ensino-aprendizagem de conceitos científicos; o papel das TICs etc. Acrescentaria a esses a própria teoria do conhecimento científico (epistemologia) como um 
grande objeto de pesquisa, que também poderia se desdobrar em objetos mais específicos, tais como: o papel da História da Ciência no Ensino de Física, a compreensão pública da ciência, entre outros.

Do enunciado acima, deduzimos o pressuposto de que os objetos de pesquisa são de diversas naturezas; vemos também que esse pesquisador não os enquadra nas temáticas determinadas nos eventos da área, mas acaba apresentado sua própria organização, começando por grandes temáticas, com problemas específicos que provavelmente têm diferenças metodológicas e de conteúdo. Essas grandes temáticas podem tratar sobre contextos, processos e teorias do conhecimento. Contextos, no sentido de que a pesquisa, por exemplo, com grupos de alunos em diferentes níveis educacionais, exige particularidades; assim, quando o sujeito fala em "formação de professores" pressupõe que há diferenças em estudar a formação inicial ou continuada de professores. Processos, no sentido de que, em geral, os processos de ensino e de aprendizagem precisam ser estudados em todos os níveis educacionais. Assim, quando ele cita "ensino-aprendizagem de conceitos científicos" entende-se que há aspectos gerais como, por exemplo, a linguagem, a interação em sala de aula, entre outros, embora estes processos, entendidos como objeto de estudo, estejam presentes nos diversos contextos. Teorias do conbecimento cientifico, no sentido de ampliar a compreensão do caráter interdisciplinar da área de ensino, quando ele fala em "formas de tratar os conteúdos", por exemplo, a partir da história da ciência, se entende que é preciso estudar especificamente a natureza do conteúdo a ser ensinado.

Nesse mesmo sentido, enquadramos também P6, P9 e P12 que, embora não classifiquem os objetos em gerais e específicos, como o pesquisador acima, falam dos objetos como sujeitos e relações entre sujeitos mediados pelo conteúdo, em determinados contextos escolares, em concordância com as grandes áreas temáticas de "objetos" apresentadas no depoimento anterior.

P6: Estudantes, professores, relações entre estudantes e professores, relações entre estudantes professores e conteúdos, conteúdos científicos e meta-científicos ensinados, escola, espaços não formais, materiais didáticos, mediadores em espaços não formais, entre outros.

P9: São todos os envolvidos na educação formal e não formal (alunos, professores de todos os níveis, mediadores em museus e centros de ciência etc.), suas ações educativas, seus ambientes de trabalho, suas relações com outros no contexto em que trabalham e com o contexto mais amplo e também os materiais de ensino e de divulgação do conhecimento científico.

P12: - Processos cognitivos situados em ambientes formais e não formais de ensino de Física/ ciências; - Desenvolvimento de linguagens e de dispositivos Didáticos de ensino de física/ ciências; - Procedimentos discursivos de apropriação e de circulação do conhecimento físico/ cientifico; - Processo epistemológico e ontológico de construção, e circulação do conhecimento físico/cientifico; - Modelização de dispositivos pedagógicos para situações culturais e de educação popular. 
O segundo sentido não descreve os objetos em relação a um propósito específico, mas os agrupa nas áreas temáticas definidas nos eventos acadêmicos e que permitem socializar resultados de pesquisa. Isso coincide com a perspectiva anterior, no sentido de que, certamente, são múltiplos os objetos de pesquisa e diversos os campos de atuação dos pesquisadores. Mas essa perspectiva não considera a ideia explícita de que alguns objetos gerais contêm objetos específicos, mas leva em conta a existência de campos que representam interesses comuns no interior da comunidade acadêmica da área. Note-se como os pesquisadores P13 e P14 descrevem conjuntos de áreas temáticas, mas com diferentes critérios. Para P13 são as áreas temáticas dos eventos acadêmicos; P14 as relaciona à característica interdisciplinar da área,

P13: As mesmas áreas temáticas do EPEF (Encontro de Pesquisa em Ensino de Física). As quais são: - Ensino/ Aprendizagem/ Avaliação em Física;

- Formação e prática profissional de professores de Física; - Filosofia, História e Sociologia da Ciência e o Ensino de Física; - Física e Comunicação em práticas educativas formais, informais e não formais; Linguagem e cognição no Ensino de Física; Tecnologias da informação e comunicação e o ensino de física; Didática, Currículo e inovação educacional no ensino de física; - Ciência, Tecnologia, Sociedade e Ambiente e o ensino de Física; - Políticas Públicas em Educação e o ensino de Física; - Questões teórico-metodológicas da pesquisa em Ensino de Física.

P14: O Ensino de Física, sendo uma área inerentemente multidisciplinar, aborda uma ampla variedade de temas dentre os quais, pode-se citar:

- Questões teórico-metodológicas na Pesquisa em Ensino de Física; - Inovação educacional no ensino de Física (entre outras); - Pesquisa sobre integração de tecnologias no Ensino de Física; - Pesquisa sobre Práticas educativas em Física em espaços formais e não-formais de Educação; - Pesquisa sobre a integração de Experimentos na Sala de Aula; - A Avaliação do Ensino e da Aprendizagem em Física; - Formação Inicial e Continuada do Profissional em Física; - História, Filosofia e Sociologia da Ciência e o Ensino de Física.

A principal diferença em relação ao sentido anterior é que, quando se fala em objetos gerais que se desdobram, pode-se entender que os problemas específicos dependem, necessariamente, de um problema geral e oferecem pequenas soluções que vão contribuir para um grande propósito. Entretanto, nesse caso, quando se fala em áreas temáticas, que englobam interesses de pesquisa, esses diversos interesses podem não estar necessariamente ligados entre si, o que tem influência na maneira como se entendem as linhas de pesquisa.

O terceiro sentido fala de problemas específicos em relação a seus próprios campos de atuação. Embora se possa dizer que se encaixam dentro das áreas temáticas já mencionadas nos dois grupos anteriores, interpretamos as respostas com sentidos diferentes, ao perceber que os pesquisadores ou não se sentem "autorizados" para falar de objetos de pesquisa em outros campos diferentes ao seu campo de atuação ou entendem que os objetos de pesquisa de seus campos são aplicáveis aos demais campos ou áreas temáticas.

Nessa perspectiva os pesquisadores P11, P15, P7 e P1 falam das pes- 
quisas que desenvolveram na área temática na qual atuam, como por exemplo, formação de professores, inclusão ou desenvolvimento de sequências de atividades para o ensino da física, em nível médio ou universitário.

P11: Na área de Formação de Professores: - concepções de educadores e de educandos, planejamento e controle da aprendizagem, - gestão do trabalho pedagógico, - resultados de ações pedagógicas.

P15: Alguns objetos (os que têm atuado): - Melhoria da prática pedagógica do professor, $-\mathrm{Na}$ formação inicial, $-\mathrm{Na}$ formação continuada

Nesse caso os pesquisadores referem-se à área temática de formação de professores, com descritores diferenciados: P11 fala em alguns aspectos da aprendizagem de aspectos pedagógicos dos futuros professores, entendendo que os aspectos da formação de professores atravessam todos os níveis de formação nesse campo; entretanto, P15 foca o problema na melhoria da prática pedagógica, mas diferenciando entre formação inicial e continuada.

Por outro lado, P7 e P1 referem-se à área de ensino e aprendizagem da física: P7 fala na transposição didática como o grande objeto de pesquisa, com as suas consequências em termos de processos de comunicação em sala de aula; P1 fala em diversos aspectos, como sequências de atividades para o ensino, aspectos curriculares e aspectos de interação em sala de aula.

P7: Creio que o grande objeto de pesquisa do ensino de física é a questão da transposição didática e a criação de analogias e metáforas para realizar tal transposição. A temática da inclusão é transversal, perpassando e contribuindo para uma reflexão acerca da transposição didática e da criação de metáforas e analogias mais significativas para o ensino de física de todos os alunos. De forma implícita, a comunicação ou criação de situações acessíveis de comunicação é um objeto de pesquisa do ensino de física.

P1: - Desenvolvimento, implementação e validações de sequências de ensino-aprendizagem (TLS); - Design-Based-Research (DBR); Inovação curricular e tópicos de Física moderna e contemporânea no ensino médio; Fatores docentes; - Motivação e relações com o saber; Representação multimodal.

O quarto sentido entra em conflito com a questão em si, uma vez que discute a própria possibilidade de listar "objetos de pesquisa". P8 e P10 sentem-se impedidos de responder à questão, anunciando que não existe uma resposta, uma vez que os objetos de pesquisa relacionam-se com as pesquisas de todos os pesquisadores da área, o que é difícil de listar, ou, pelo menos, são inúmeros.

P8: São inúmeros, desde os sujeitos de pesquisa (alunos, professores, formuladores de políticas públicas) passando por currículos, escolas, espaços não formais, etc.

P10: A resposta inclui um número muito grande de itens, se consideradas as pesquisas de todos os pesquisadores da área, o que inclusive é difícil de estabelecer. Acredito que a tentativa de responder essa questão, por si já pode constituir uma tese. 
Por outro lado, P4 assim se pronuncia:

P4: Pesquisa não é coleta ou levantamento de dados. Toda pesquisa se baseia numa teoria/ problema.

Nesse último caso, interpretamos que a pergunta pelos “objetos de pesquisa”, possivelmente, gerou-lhe um desconforto ao entender que tais objetos podem estar sendo entendidos como as fontes de informação ou os modos de coletar um conjunto de dados e, portanto, chama a atenção para o fato de que a pesquisa vai além da coleta ou levantamento de dados, precisando uma teoria e um problema, o que pode significar que a questão estaria mais bem formulada, se perguntássemos pelos problemas a serem enfrentados pela pesquisa. Neste mesmo sentido, interpretamos a resposta do P5:

\section{P5: Não entendi essa questão.}

Essa resposta significa que, para ele, essa é uma questão confusa. Perguntar pelos "objetos de pesquisa" da pesquisa em ensino de física pode não fazer sentido. Provavelmente faria mais sentido falar dos processos de pesquisa ou os problemas que se enfrentam com a pesquisa.

Ao comparar os quatro sentidos, concluímos, em primeiro lugar, que para os pesquisadores é difícil dar uma resposta a essa questão, uma vez que, para alguns os "objetos de pesquisa" da pesquisa em ensino de física são múltiplos, não definidos explicitamente e tendem a aumentar, na medida em que aumenta a pesquisa na área - e isso depende dos interesses dos pesquisadores que, por sua vez, relacionam-se com sua formação, as condições de pesquisa, os campos de atuação e as visões de ciência e ensino de ciências que eles têm, por exemplo. Alguns falam somente dos objetos de pesquisa que têm estudado em seus casos particulares, e para outros, a pergunta não faz sentido.

Apesar disso, e com o propósito de identificar possíveis temáticas a serem ensinadas em um curso de Didática da Física na formação inicial de professores, buscamos os principais consensos entre os pesquisadores; desta vez, procurando frequências de aspectos mencionados, não somente na resposta à questão seis, mas complementando com resultados de suas pesquisas publicadas na última década.

Percebemos que não há aspectos predominantes, mas um conjunto de campos de ação que caracterizam o fazer dos pesquisadores. Campos de ação como: formação inicial e continuada de professores; atuação do professor em diferentes níveis educacionais, como fundamental, médio e superior; em condições formais e não formais; para estudantes regulares ou especiais; o estudo sobre os objetivos de ensinar física: ensinar para que o aluno aprenda a física, para que se forme um cidadão por meio do aprendizado da física, para que se forme como professor de física ou como profissional de outras áreas (engenharia, medicina etc.), o que tem a ver, também, com a organização de currículos e posicionamentos políticos sobre a importância do ensino de física. 
Também identificamos referência à pesquisa sobre os processos de ensino e aprendizagem com foco: nos processos cognitivos de professores e estudantes; na comunicação em sala de aula; no planejamento e desenvolvimento de sequências didáticas; na criação de dispositivos didáticos; no uso de recursos como laboratórios e tecnologias; na relação professor/aluno/conteúdo; na divulgação científica; na transposição didática, entre outros.

Interpretamos esses resultados como a evidência da necessidade de formar os futuros professores, que se espera que sejam pesquisadores de sua prática, em aspectos como: a compreensão das particularidades do ensino de física em diferentes níveis educacionais; a aprendizagem para o enriquecimento da interação em sala de aula, que implica na compreensão de todos os elementos que intervêm para desenvolver um determinado curso; os objetivos de ensinar a física para responder a fins educacionais, que vão além do simples aprendizado da física, compreendendo também, por exemplo, políticas e organizações curriculares.

Com base nesse resultado, podemos dizer que, na formação de professores de física, é preciso considerar aspectos que lhes permitam adquirir conhecimentos nesses aspectos, mas de forma integrada. Isto é, de forma que eles considerem o ensino de física em diversos contextos, que compreendam a função do ensino da física nesses contextos, mas também que aprendam sobre aspectos específicos da interação em sala de aula, tendo o conhecimento da física como mediador de tal interação - temas nos quais existe um importante acúmulo de resultados produzidos pelos pesquisadores questionados.

Para entender mais um pouco esses resultados, apresentamos, a seguir, as características profissionais dos pesquisadores estudados, descrevendo os tipos de pesquisa que desenvolveram e os principais tipos de referenciais que costumam utilizar.

\section{Características profissionais dos pesquisadores estudados}

Ao comparar a formação acadêmica dos sujeitos desta pesquisa, encontramos uma grande diversidade de combinações entre a formação inicial, o mestrado, o doutorado e o pós-doutorado, conforme representado no Quadro 2, sendo a opção mais comum, a formação de Licenciado em física, com mestrado em ensino de ciências e doutorado em Educação.

Quadro 2 - Opções de combinações de formação acadêmica dos pesquisadores em ensino de física

\begin{tabular}{|c|c|c|c|}
\hline Graduação & Mestrado & Doutorado & $\begin{array}{l}\text { Pós-doutorado/teses } \\
\text { livre docência }\end{array}$ \\
\hline $\begin{array}{l}\text { - Licenciatura em } \\
\text { física. } \\
\text { - Bacharel/Física } \\
\text { - Engenharia }\end{array}$ & $\begin{array}{c}\text { - Ensino de ciências, } \\
\text { - Ensino de física } \\
\text { - Física } \\
\text { - Psicologia } \\
\text { - Educação }\end{array}$ & $\begin{array}{c}\text { - Educação } \\
\text { - Física } \\
\text { - Ensino de física } \\
\text { - Ciências } \\
\text { - Didática das ciências } \\
\text { - Ensino de ciências }\end{array}$ & $\begin{array}{c}\text { Principalmente } \\
\text { ligados às linhas de } \\
\text { pesquisa }\end{array}$ \\
\hline
\end{tabular}


No total, os 15 pesquisadores estudados atuam em 19 grupos de pesquisa, todos reconhecidos pelo CNPq. Esse fato garante a importância e o impacto das pesquisas realizadas por eles. A formação acadêmica e o pertencimento aos diferentes grupos de investigação em diferentes universidades já anunciam uma diversidade de perspectivas que ocorre nesse campo, situação que verificamos ao mapear as linhas de pesquisa. Nesta fase, percebemos que a quantidade de linhas, por cada pesquisador, varia entre duas e quatorze, constituindo-se em 65 diferentes linhas de pesquisa, sendo que a maioria delas não é, exclusivamente, sobre o ensino da física, mas da área geral de ensino de ciências, em diversos contextos e para diversas problemáticas.

Em geral, esses pesquisadores trabalham com questões como: estudos de experiências realizadas em sala de aula, desenvolvimentos teóricos da didática, transposição didática, mudança conceitual, modelos psicopedagógicos, construtivismo, uso de referenciais epistemológicos, uso de referenciais semióticos, cognição, discurso, subjetividade, comunicação, perspectiva sociocultural da física, relações entre educação, ciência e tecnologia, relação entre informação, ciência e tecnologia, questões sociocientíficas, história dos conceitos científicos, estratégias de ensino a partir da história e da filosofia da ciência, relação educação/internet, modelagem e uso de recursos tecnológicos.

Esse resultado concorda com o que observamos na questão três, na qual foi solicitado aos pesquisadores indicarem as áreas temáticas nas quais se inscrevem suas pesquisas, apresentando-lhes as opções de temáticas estabelecidas nos eventos acadêmicos EPEF e SNEF, conforme informação descrita no Tabela 1.

TABELA 1 - Porcentagem de pesquisadores que se inscrevem nas áreas temáticas de pesquisa em ensino de física

\begin{tabular}{|l|c|}
\hline \multicolumn{1}{|c|}{ Áreas temáticas de pesquisa em ensino de física } & \% pesquisadores \\
\hline Ensino/ Aprendizagem/ Avaliação em física & 80 \\
\hline Formação e prática profissional de professores de física & 73 \\
\hline Linguagem e cognição no ensino de física & 60 \\
\hline Didática, currículo e inovação educacional no ensino de física & 47 \\
\hline Filosofia, história e sociologia da ciência e o ensino de física & 40 \\
\hline $\begin{array}{l}\text { Questões teórico-metodológicas da pesquisa em ensino de } \\
\text { física }\end{array}$ & 26 \\
\hline $\begin{array}{l}\text { Ciências, tecnologia, sociedade e ambiente e o ensino de } \\
\text { física }\end{array}$ & 26 \\
\hline
\end{tabular}




\begin{tabular}{|l|c|}
\hline $\begin{array}{l}\text { Física e comunicação em práticas educativas formais, } \\
\text { informais e não-formais }\end{array}$ & 26 \\
\hline $\begin{array}{l}\text { Tecnologias da informação e comunicação e o ensino de } \\
\text { física }\end{array}$ & 20 \\
\hline Políticas públicas em educação e o ensino de física & 20 \\
\hline $\begin{array}{l}\text { Outras: } \\
\text { - Ensino de ciências em espaços não formais } \\
\text { - Inclusão de alunos com necessidades educacionais } \\
\text { especiais no ensino de ciências/física }\end{array}$ & 26 \\
\hline
\end{tabular}

Por outro lado, ao perguntar pelos instrumentos de coleta de dados e métodos de análise utilizados, encontramos a pesquisa qualitativa como principal abordagem de investigação, sendo a entrevista o instrumento mais utilizado em suas diversas modalidades: estruturada, semiestruturada, aberta, individual e coletiva, seguida do uso do questionário aberto e fechado, vídeo-gravações de aula, estudos de grupo focal e observação etnográfica (porcentagens de frequência apresentadas no Gráfico 1).

GRÁFICO 1 - Porcentagem de pesquisadores que utilizam os instrumentos mais comuns para coleta de dados.

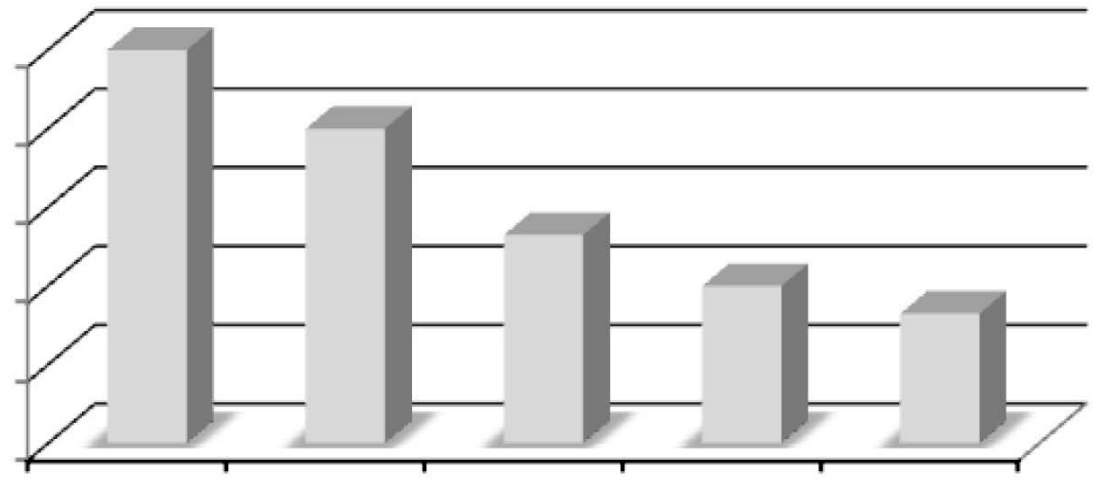

Entrevista Questionário Vídeos de Grupo focal Observação

Fonte: elaborado pelos autores deste artigo

É importante observar que os pesquisadores da amostra muitas vezes utilizam vários instrumentos simultaneamente; isso depende, entretanto, dos temas de pesquisa e das amostras consideradas em seus estudos.

As formas de entender a pesquisa, constituir e analisar dados dependem muito do instrumento e do problema de estudo. Além disso, vários métodos podem ser utilizados para analisar dados obtidos a partir de um mesmo 
tipo de instrumento. Sendo assim, não é possível falar de métodos mais ou menos frequentes, mas das diferentes opções possíveis mencionadas pelos pesquisadores. A mais comum é a pesquisa qualitativa, a partir da Análise de Conteúdo, uma vez que a coleta de dados geralmente permite a construção de textos, mas esses textos também podem ser analisados e constituídos a partir da perspectiva da Análise de Discurso, com diversos dispositivos de análise ou ainda por meio da Análise Textual Discursiva.

Já para a constituição de dados que representam frequências ou ausências e que possibilitam contagens, utilizam-se métodos de análises estatísticas, que permitem tanto resultados quantitativos quanto qualitativos, utilizando desde técnicas descritivas analíticas até o uso de softwares especializados, que permitem obter conclusões qualitativas. Pelo menos a metade dos pesquisadores menciona a triangulação ou comparação de dados qualitativos e quantitativos como método de análise. Também encontramos o uso de análise multimodal, aplicada a dados obtidos a partir de gravações de vídeo, que permitem estudar as diversas formas de expressão dos pesquisados.

Essa breve descrição evidencia uma área complexa com múltiplos desdobramentos, se pensarmos na combinação de cada um dos campos com cada um dos problemas relacionados anteriormente e a partir de diversas formas de constituição e análise de dados. Tal situação leva-nos a ressaltar o grande desafio no momento de decidir o que ensinar para formar professores e pesquisadores da área, se considerarmos que, na condição de professores universitários, devemos utilizar os conhecimentos produzidos pela pesquisa, tanto para a formação de professores, como nos ensinos Fundamental e Médio, já que é esse o público que os futuros professores atenderão.

Outro aspecto indagado foram os principais tipos de referenciais teóricos utilizados pelos pesquisadores, item que foi analisado com base na produção de artigos a partir do ano 2000, selecionados com o critério de que a partir do título, do resumo e das conclusões fosse possível evidenciar um trabalho sobre o ensino e a aprendizagem da física.

Dada a quantidade de informação, (15 pesquisadores cada um com uma média de 20 referenciais selecionados), analisamos o texto utilizando o software Atlas.ti, que é especializado para estudos qualitativos de materiais extensos. Depois de analisar o sentido do título e os autores das referências mencionadas pelos pesquisadores, procuramos analisar as ideias gerais que os pesquisadores defendem ao se fundamentar em tais referenciais. Assim, fomos criando categorias e famílias de categorias de referenciais teóricos, o que nos permitiu relacionar quatro famílias de categorias, cuja descrição geral é:

- Familia 1. Ensino de ciências/física, com as categorias: Construtivismo; Física; Física moderna no nível médio; fundamentos da área de ensino de ciências; História e Filosofia no ensino; Inclusão; In- 
teração em sala de aula; Modelos, Representações e Analogias; Perspectiva sociocultural; Pré-concepções; Uso de TICs; Visões de natureza de ciência; Espaços não formais; Tendências metodológicas de ensino e aprendizagem.

- Família 2. Saberes interdisciplinares que servem ao ensino de ciências, com as categorias: Educação; Ensino de matemática; Filosofia e epistemologia; História; Linguagem; Psicologia da aprendizagem; Sociologia.

- Família 3. Formação de professores, com as categorias: Formação continuada; Formação inicial; Teoria da profissão docente.

- Família 4. Modalidades de pesquisa, com as categorias: Pesquisa qualitativa; Perspectivas de desenvolvimento da pesquisa.

O primeiro fato que salientamos é que a área de ensino de ciências, ainda que com especialidade em ensino de física, é multidisciplinar, no sentido de que, para resolver os problemas próprios desse campo, faz-se necessário utilizar de forma integrada diversos campos de conhecimento. Observamos que os referenciais utilizados não são exclusivamente resultados de pesquisa em ensino de física, mas para produzir esse tipo de pesquisa, é preciso considerar conteúdos da educação, das ciências exatas, das ciências humanas e da própria área de ensino de ciências, que apresenta um importante desdobramento de tópicos.

Todas essas observações nos levam a considerar a importância da formação de futuros professores, a partir da conscientização sobre a existência dessas famílias e categorias de referenciais, com a respectiva formação de critérios para selecionar e combinar adequadamente os referenciais na solução dos diversos problemas do ensino de física.

Daí a necessidade de formá-los para enfrentarem a diversidade de problemas com as possibilidades de abrir caminhos para sua solução. Certamente, não será possível ensinar os licenciandos a resolverem todos os problemas existentes, mas sim contribuir na criação de uma visão ampla e flexível a respeito de como abordá-los.

\section{CONCLUSÕES}

Deduzimos que os "objetos de pesquisa" da pesquisa em ensino de física podem ser agrupados em grandes temáticas integradoras: uma que trata dos diversos contextos onde são estudados os problemas de ensino e aprendizagem da física; outra que define os objetivos de ensinar física; e outra que aborda os processos de ensino e aprendizagem em sala de aula. Portanto, esse pode ser um critério de organização de conteúdos a serem trabalhados em um curso de Didática da Física. 
Além disso, constatamos o caráter multidisciplinar da pesquisa na área, ao entender que os pesquisadores consideram resultados de pesquisa em ensino de física, mas também aportes vindos de disciplinas da educação, das ciências exatas, das ciências humanas, e da área de ensino de ciências. Isso significa que o ensino da Didática da Física deve ter também esse caráter multidisciplinar, a fim de que o futuro professor seja formado em critérios que lhe permitam fazer uso de conhecimentos de diversas disciplinas na solução de problemas específicos do ensino e da aprendizagem da física.

É preciso oportunizar aos futuros professores uma visão ampla dos objetos de pesquisa nesse campo, a fim de serem educados em critérios que lhes permitam decidir de maneira consciente e fundamentada o que ensinar e como ensinar; quer dizer, que tenham critérios para selecionar conteúdos, metodologias e referenciais teóricos apropriados na resolução dos problemas que possam vir a ter em seu exercício profissional e sobre os quais provavelmente a literatura já apresenta avanços.

\section{NOTAS}

${ }^{1}$ Sistema de informação do CNPq, disponibilizado publicamente por meio da internet, que integra bases de dados de Currículos, Grupos de pesquisa e Instituições relacionadas com a pesquisa.

\section{REFERÊNCIAS}

ATLAS.ti Qualitative Data Analysis. Scientific Software Development GmbH, Copyright C 2013.

BARDIN, L. Análise de conteúdo. Lisboa: Edições 70, 2002.

DELIZOICOV, D. Pesquisa em ensino de ciências no Brasil: fatores que determinaram sua constituição e suas características segundo pesquisadores brasileiros. In: NARDI, R. (Org.) A pesquisa em ensino de ciências no Brasil: alguns recortes. São Paulo: Escrituras, 2007, p.413-449.

ENCONTRO NACIONAL DE PESQUISA EM ENSINO DE CIÊNCIAS, 7., Florianópolis, 2009. Atas... Disponível em: < http://posgrad.fae.ufmg. $\mathrm{br} /$ posgrad/viienpec/>. Acesso em: 18 out. 2011.

ENCONTRO NACIONAL DE PESQUISA EM ENSINO DE CIÊNCIAS, 8., Campinas, 2011. Atas... Disponível em: <http://www.nutes.ufrj.br/abra$\mathrm{pec} /$ viiienpec/index.htm>. Acesso em: 18 out. 2011.

ENCONTRO DE PESQUISA EM ENSINO DE FÍSICA, 10., Londrina, 2006. Atas... Disponível em: <http://www.sbf1.sbfisica.org.br/eventos/ epef/x/atas/>. Acesso em: 18 out. 2011.

ENCONTRO DE PESQUISA EM ENSINO DE FÍSICA, 11., Curitiba, 2008. 
Atas... Disponível em: <http://www.sbf1.sbfisica.org.br/eventos/epef/xi/ atas/>. Acesso em: 18 out. 2011.

GIL, A. C. Métodos e técnicas de pesquisa social. 6. Ed. São Paulo: Editora Atlas, 2008.

MEGID NETO, J. Três décadas de pesquisas em educação em ciências: tendências de teses e dissertações (1972-2003). In: NARDI, R. (Org.) A pesquisa em ensino de ciências no Brasil: alguns recortes. São Paulo: Escrituras, 2007, p.341-355.

MORAES, R.; GALIAZZI, M. C. Análise textual discursiva. Ijuí: Editora Unijuí, 2007.

NARDI, R. A área de ensino de ciências no Brasil: fatores que determinaram sua constituição e suas características segundo pesquisadores brasileiros. 2005. 170 f. Tese (Livre Docência) - Faculdade de Ciências, Universidade Estadual Paulista. Bauru, 2005.

NARDI R.; ALMEIDA, M.J.P.M. Investigação em ensino de ciências no Brasil segundo pesquisadores da área: alguns fatores que lhe deram origem. Pro-Posições, Campinas, v. 18, n. 1 (52) - jan./abr., 2007.

\section{Contato:}

Olga Lucía Castiblanco Abril

Universidade Distrital Francisco José de Caldas

Faculdade de Ciência e Educação. Curso de Licenciatura em Física

Carrera 3, No.26A-40, Bogotá- Colômbia

E-mail: olcastiblancoa@udistrital.edu.co 